
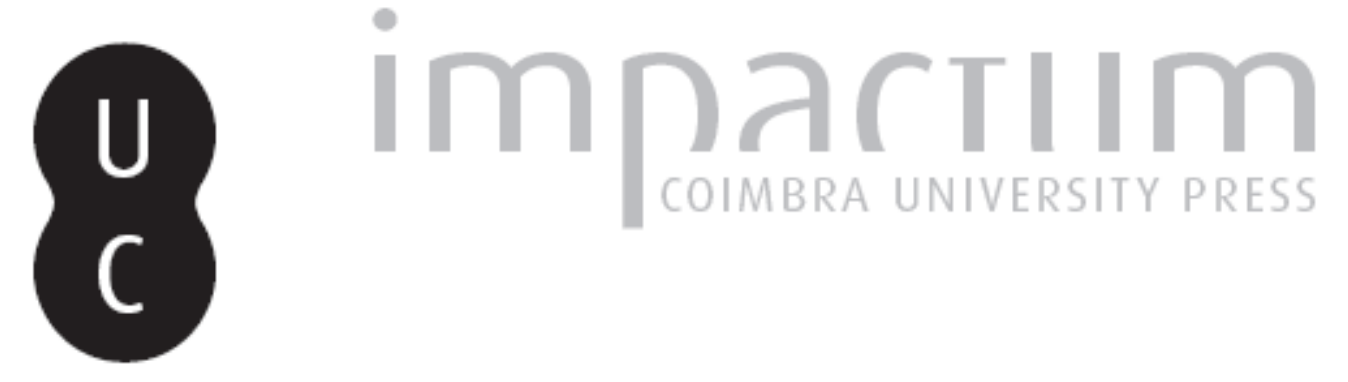

\title{
Os riscos e o sistema europeu de protecção civil
}

\section{Autor(es): $\quad$ Monteiro, Fernando Manuel Paiva}

Publicado por: Associação Portuguesa de Riscos, Prevenção e Segurança

URL persistente:

URI:http://hdl.handle.net/10316.2/36175

DOI:

DOI:http://dx.doi.org/10.14195/1647-7723_16_20

Accessed : $\quad$ 26-Apr-2023 14:54:26

A navegação consulta e descarregamento dos títulos inseridos nas Bibliotecas Digitais UC Digitalis, UC Pombalina e UC Impactum, pressupõem a aceitação plena e sem reservas dos Termos e Condições de Uso destas Bibliotecas Digitais, disponíveis em https://digitalis.uc.pt/pt-pt/termos.

Conforme exposto nos referidos Termos e Condições de Uso, o descarregamento de títulos de acesso restrito requer uma licença válida de autorização devendo o utilizador aceder ao(s) documento(s) a partir de um endereço de IP da instituição detentora da supramencionada licença.

Ao utilizador é apenas permitido o descarregamento para uso pessoal, pelo que o emprego do(s) título(s) descarregado(s) para outro fim, designadamente comercial, carece de autorização do respetivo autor ou editor da obra.

Na medida em que todas as obras da UC Digitalis se encontram protegidas pelo Código do Direito de Autor e Direitos Conexos e demais legislação aplicável, toda a cópia, parcial ou total, deste documento, nos casos em que é legalmente admitida, deverá conter ou fazer-se acompanhar por este aviso.

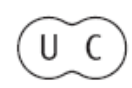




\section{territorium}

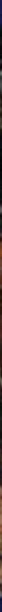

16

Revista da Associação Portuguesa de Riscos, Prevenção e Segurança 2009 


\title{
OS RISCOS E O SISTEMA EUROPEU DE PROTECÇÃO CIVIL*
}

\author{
Fernando Manuel Paiva Monteiro \\ Comandante da Academia Militar e \\ ex-Presidente do Serviço Nacional de Bombeiros e Protecção Civil
}

\section{Introdução}

Os desastres naturais e os provocados por alguma interferência humana destroem a propriedade pública e privada, causam avultados danos ao ambiente e colocam desafios consideráveis ao desenvolvimento sustentado.

Os países da União Europeia estão cada vez mais expostos a riscos de toda a espécie tanto naturais como antrópicos, susceptíveis de originar catástrofes de terríveis consequências para as suas economias, para o ambiente e, portanto, para as suas populações e seu modo de vida.

Para fazer face a ocorrências derivadas destes riscos, cada país dispõe do seu próprio sistema de protecção, mais ou menos dimensionado consoante a previsibilidade de ocorrência de catástrofes a eles associadas e as disponibilidades e meios específicos de cada um. É sabido que, para desastres de determinada dimensão, não há nenhum país que possa só por si dar resposta eficaz e atempada, pelo que, normalmente, solicita ajuda a países amigos.

É importante reter que alguns grandes desastres, num determinado país do espaço europeu, apesar de não terem um impacto directo nos outros, podem produzir impactos negativos significativos no tecido socioeconómico desse país que requeira intervenção das estruturas da EU, nomeadamente, através do fundo de solidariedade, como aconteceu em 2003 no nosso país.

Há outros desastres que têm um claro efeito simultâneo em diversos países, caso de inundações, tsunamis e furacões. Temos um exemplo claro nos últimos anos, na Europa central, o das inundações verificadas em 2002, em simultâneo, provocadas pelo Vlatva na República Checa, pelo Elba na Alemanha e pelo Danúbio em diversos países incluídos na sua bacia hidrográfica.

A estes acidentes tem vindo a ser dedicada cada vez mais atenção por parte dos poderes instituídos, dado que nos últimos anos as estatísticas confirmam que, globalmente, desde 1975, o número de desastres naturais aumentou de cerca de 75 para 300 por ano. Só os acidentes associados aos fenómenos hidrológicos subiram de 100 em 2004 para 200 em 2006.

Um relatório da Organização das Nações Unidas recentemente publicado intitulado"Redução de Riscos de Catástrofes - Balanço Mundial 2009", o primeiro do género elaborado pela organização, refere que ocorreram em 2008 mais de 300 catástrofes que fizeram 236.000 mortos e afectaram 200 milhões de pessoas. Sublinha ainda que as alterações climáticas, a degradação do ambiente e a urbanização anárquica são factores que contribuem decisivamente para potenciar os seus efeitos nefastos.

Outro aspecto a considerar são os custos dos danos provocados por este tipo de acidentes, que têm aumentado significativamente, como referem alguns relatórios entretanto conhecidos. A título de exemplo refira-se que no actual território da UE a 27 , no período de 1974 a 1978, esses custos foram de 16 mil milhões de dólares, enquanto que no período de 4 anos entre 1999 e 2003 somaram 56 mil milhões de dólares.

Face a estas estatísticas há pois que encontrar, dentro do espaço europeu, mecanismos que possibilitem actuar em conjunto em dois grandes domínios associados:

- Na prevenção dos acidentes

- Na minimização dos seus efeitos, nomeadamente numa ajuda mútua e oportuna através dos meios mais adequados.

É importante que se refira, que, à medida que o processo de aprofundamento da União Europeia se foi acentuando, foram sendo desenvolvidos mecanismos que vêm propiciando uma melhor colaboração entre os países membros, nomeadamente nas áreas económica, politica, social, da defesa e segurança, da justiça e assuntos internos e também nos últimos anos no domínio do ambiente e da protecção civil. Este processo decorre em paralelo com a assinatura de acordos bilaterais que possibilitam a cooperação em domínios pontuais.

\section{A cooperação comunitária no domínio da Protecção Civil}

O espaço geográfico da UE tem sido atingido por catástrofes de diversas categorias. A título de exemplo podemos recordar o sismo de 1980 em Itália (2739 mortos), as cheias de 1973 em Espanha (350 mortos) e os fogos florestais que com alguma regularidade fustigam em simultâneo, todos os países

* Conferência proferida durante o V Encontro Nacional e I Congresso Internacional de Riscos, durante a Mesa Redonda 1, dedicada à Protecção Civil, Prevenção e Socorro, na óptica dos ex-Presidentes do Serviço Nacional de Bombeiros e de Protecção Civil. 
do sul da Europa - Portugal, Espanha, França, Itália e Grécia. Mais recentemente, o do sismo do passado dia 06 de Abril de 2009, em Itália, que causou cerca de 300 vitimas mortais.

Face a esta realidade e cientes de que o aprofundamento de um espaço comum europeu. também devia ser feito no domínio da prevenção e mitigação dos efeitos de acidentes, os responsáveis ministeriais por esta área, lançaram em 1985 as bases para a cooperação comunitária no domínio da Protecção Civil. Desde então, várias resoluções têm sido adoptadas e vários instrumentos têm sido criados, com o objectivo de transformar o território europeu num espaço cada vez mais seguro e mais pronto a reagir a situações de emergência.

O principal objectivo dos esforços que têm sido desenvolvidos ao nível comunitário no domínio da Protecção Civil é, em traços gerais, o de garantir uma melhor protecção das populações, do ambiente e dos bens em caso de catástrofe natural, tecnológica ou ambiental.

Neste domínio podemos apontar quatro grandes áreas prioritárias ao nível da UE:

- Apoiar os esforços para a melhoria da prevenção e dos níveis de resposta desenvolvidos ao nível nacional, regional e local, pelas autoridades responsáveis pela Protecção Civil e pela gestão da resposta em situação de catástrofe;

- Contribuir para a melhoria da informação ao público com vista à sensibilização dos cidadãos europeus para questões como medidas de auto-protecção;

- Definir as bases para uma efectiva e rápida cooperação entre as estruturas nacionais de Protecção Civil sempre que se torne necessário recorrer a ajuda mútua;

- Fortalecer a coerência das acções desenvolvidas ao nível internacional e no domínio da Protecção Civil, especialmente no contexto da cooperação com todos os países da Europa e ainda com os parceiros do Mediterrâneo.

Ao nível da Comissão, e sob a alçada da Direcção-Geral do Ambiente, foi criada a Unidade de Protecção Civil (UPC), órgão com responsabilidades de gerir os aspectos comunitários relacionados com a Protecção Civil, garantir a observância dos instrumentos legislativos existentes e fomentar a cooperação e a articulação entre os Estados-membros da UE.

Mediante propostas da Comissão, desde 1997 que o Conselho da UE tem vindo a melhorar as bases de trabalho comunitário no domínio da Protecção Civil, nomeadamente através do estabelecimento dos
Programas de Acção Comunitários. Pretende-se que estes programas funcionem como uma ferramenta de trabalho essencial onde estão expressas as áreas prioritárias de intervenção em termos comunitários e as directrizes a seguir.

Como resultado deste esforço conjunto tem sido possível alcançar vários patamares de sucesso, muitos deles com um impacto directo e real no dia-a-dia dos cidadãos europeus. São de referir:

Numero Único Europeu de Emergência - 112

Através da Directiva Comunitária 91/396/EEC, de 2 de Julho, foi criado o número de telefone de emergência único - 112, o qual deverá ser implementado por todos os Estados-Membros da UE.

O número europeu de emergência está praticamente instituído em quase todos os EstadosMembros, embora em alguns casos funcione em simultâneo com outros números de emergência, geralmente associados aos diferentes sistemas: polícia, ambulâncias e incêndios.

Facilmente verificamos a importância desta medida se atentarmos a que cerca de 90 milhões de europeus se deslocam anualmente para fora do seu país na Europa comunitária.

Manual Operacional de Protecção Civil

Esta simples ferramenta consiste, como aliás o próprio nome indica, num manual que inclui, entre outras, informação detalhada sobre:

- Os vários pontos de contacto nacionais para a Protecção Civil dos vários Estados-Membros, disponíveis $24 \mathrm{H}$;

- Os membros do grupo de peritos para fogos florestais.

\section{Rede Permanente de Correspondentes Nacionais/ Comité de Gestão do Programa de Acção e do Mecanismo Comunitário de Protecção Civil}

Trata-se de uma rede de representantes nacionais constituída por elementos oriundos das estruturas nacionais responsáveis pela Protecção Civil e pode ser considerada como a primeira rede de Protecção Civil - coerente e coordenada - ao nível comunitário.

\section{Mecanismo Europeu de Protecção Civil}

Em Setembro de 2001, a Comissão Europeia propôs a criação de um mecanismo comunitário destinado a facilitar uma cooperação reforçada, dentro e fora da União Europeia, em intervenções de socorro no âmbito da protecção civil que pudessem exigir uma resposta urgente.

O Mecanismo destina-se, assim, a contribuir para assegurar uma maior protecção, não só das pessoas, mas também do ambiente e dos bens, nomeadamente, 
do património cultural, em situações de emergência grave, como sejam catástrofes naturais, tecnológicas, radiológicas ou ambientais, ocorridas dentro e fora da União Europeia, através de uma melhor coordenação das intervenções de socorro por parte dos Estados-Membros e da Comunidade.

O Mecanismo Comunitário de Protecção Civil veio a ser aprovado através da Decisão do Conselho da União Europeia 2001/792/CE, de 23 de Outubro de 2001 , entrou em vigor no dia 1 de Janeiro de 2002 e assenta fundamentalmente na seguinte série de elementos e acções:

- Criação de um Centro de Informação e Vigilância no seio da Comissão, acessível e pronto a intervir imediatamente $24 \mathrm{~h} / 24 \mathrm{~h}$, encarregue de acompanhar o desenrolar dos acontecimentos e fornecer informações - MIC (Monitoring and Information Centre);

- Recenseamento preliminar das equipas de intervenção disponíveis nos serviços da protecção civil ou em outros serviços de urgência dos Estados membros;

- Programa de formação destinado a reforçar as capacidades de reacção aos acontecimentos e melhorar a coordenação e a transmissão de conhecimentos entre as equipas de intervenção;

- Mobilização de equipas de avaliação e de coordenação que poderão ser enviadas no mais breve espaço de tempo possível de acordo com as necessidades;

- Sistema comum de comunicação de urgência entre as autoridades dos Estados-Membros responsáveis pela Protecção Civil e os serviços competentes da Comissão.

Com a aprovação do Mecanismo, a Comissão Europeia passou a trabalhar em estreita cooperação com as autoridades dos Estados Membros, de modo a que, em caso de emergência grave, o Estado requerente de ajuda dirija o seu pedido à Comissão e possa, doravante, ter acesso imediato aos recursos disponíveis na Comunidade, sem necessidade de perder tempo a procurar e a contactar diversas formas de ajuda.

No entanto, para poderem intervir eficazmente em caso de emergência, os Estados Membros devem:

- Identificar previamente as equipas que poderão estar, em princípio, disponíveis para essas intervenções ou que poderão ser constituídas para intervir num prazo muito curto - 12 horas - após o pedido de assistência;

- Seleccionar peritos;

- Fornecer informações sobre essas equipas e peritos, bem como os recursos médicos disponíveis;

- Fornecer, caso seja possível, outros meios de intervenção que possam estar disponíveis;
- Nomear as autoridades competentes, designar os pontos de contacto e dar conhecimento à Comissão.

De acordo com a decisão que o institui, o Mecanismo pode ainda ser utilizado no âmbito da gestão de crises referidas no Título $V$ do Tratado da UE (missões de carácter humanitário ou de evacuação de cidadãos, missões de manutenção da paz; missões executadas por forças de combate para gestão de crises incluindo operações de restabelecimento da paz).

\section{Regras Comuns do Mecanismo Comunitário de Protecção Civil}

No âmbito da Decisão acima referida, e nos termos do seu art. 8ํ, a Comissão definiu Regras Comuns de intervenção para o Mecanismo, que procuram definir procedimentos em sete áreas específicas:

- Recursos disponíveis;

- Centro de informação e monitorização (MIC);

- Sistema de comunicações de emergência;

- Equipas de reconhecimento e de coordenação, incluindo critérios para a selecção de peritos;

- Programa de formação;

- Informação sobre recursos médicos;

- Intervenções dentro e fora da comunidade.

\section{Monitoring and Information Centre - MIC}

O MIC está sediado em Bruxelas nas instalações da Comissão Europeia e funciona como um centro de vigilância e alerta, operacional $24 \mathrm{~h} /$ dia. Em termos de pessoal, o MIC mantém sempre dois funcionários de serviço que, após notificação emitida pelo ponto de contacto da Comissão (Oficial de Segurança), estarão operacionais em menos de 1 hora.

Neste contexto, importa referir que o MIC não possui qualquer responsabilidade operacional, pelo que apenas mantém pessoal $24 \mathrm{~h} /$ dia em situações de emergência que exijam um acompanhamento permanente. As tarefas quotidianas do MIC incluem, nomeadamente:

- Actualizar regularmente as informações fornecidas pelos Estados participantes sobre as equipas de intervenção e os peritos identificados e seleccionados, bem como sobre outros meios de intervenção e recursos médicos que possam estar disponíveis para intervenção;

- Centralizar as informações fornecidas sobre a capacidade dos Estados participantes para manterem uma produção de soros e vacinas ou outros recursos médicos necessários, bem como sobre as reservas existentes que poderão estar disponíveis para intervenção em caso de 
situação de emergência grave, e reunir estas informações no sistema de informação seguro ao nível adequado;

- Actualizar regularmente os seus métodos de trabalho e procedimentos de emergência;

- Contactar os pontos de contacto nacionais dos Estados participantes a fim de, se necessário, preparar um relatório sobre emergências graves;

- Participar no programa de registo dos ensinamentos extraídos das intervenções realizadas e difundir os respectivos resultados;

- Tomar parte na preparação, organização e acompanhamento das acções de formação;

- Tomar parte na preparação, organização e acompanhamento dos exercícios no terreno e dos exercícios teóricos.

Sempre que o MIC é notificado sobre a ocorrência ou eminência de uma situação de emergência ou recebe um pedido de apoio internacional:

- Recolhe toda a informação disponível e procede à posterior disseminação pelos vários estados participantes no Mecanismo;

- Procura apoiar e facilitar a mobilização das equipas de intervenção, peritos e equipamento.

Algumas das Intervenções do Mecanismo

- Cheias na Europa Central em 2002;

- Sismo na Argélia (Maio 2003);

- Cheias no sul de França (Dezembro 2003);

- Sismo no Irão (Dezembro 2003);

- Sismo em Marrocos (Fevereiro 2004);

- Incêndios florestais Portugal (Verão 2003, 2004 e 2005);

- Incêndios florestais Marrocos (Verão 2004);

- Sismo e Tsunami no Sudoeste Asiático (Dezembro 2004);

- Cheias na Roménia, Bulgária e Geórgia (Maio e Junho 2005);

- Sismo na China (Maio 2008).

\section{Reformulação do mecanismo comunitário de Protecção Civil}

Após a intervenção do Mecanismo nas operações de socorro associadas ao tsunami no sudoeste asiático, passou a ser notória a necessidade de se implementarem melhorias no modo de funcionamento do Mecanismo. Assim desencadeou-se um processo de reforma que durou até 2007 , altura em que é aprovada a reformulação do Mecanismo Comunitário de Protecção Civil através da decisão do Conselho de 8 de Novembro de 2007, de modo a conferir maior coerência e eficácia à resposta da União Europeia a situações de emergência.
A decisão inclui um importante conjunto de elementos e medidas de que se destacam:

- A criação e gestão de um Centro de Informação e Vigilância (CIV) acessível e pronta a reagir imediatamente 24 horas por dia;

- A criação e gestão de um Sistema Comum de Comunicação e Informação de Emergência (CECIS - Common Emergency Communication and Information System) para permitir a comunicação e a troca de informação entre o CIV e os Estados Membros;

- Contribuir para o desenvolvimento de sistemas de detecção e alerta precoce de catástrofes;

- Identificação de equipas, módulos e meios de intervenção dos Estados Membros

- Criação e implementação de programas de formação e acções de formação e sensibilização;

- Constituição de equipas de avaliação e/ ou coordenação;

- Financiamento de recursos complementares de transporte;

- Assistência consular a cidadãos da EU em emergências graves em países terceiros.

A decisão define ainda as obrigações que os Estados Membros devem satisfazer, para que os seus contributos para acções comunitárias no domínio da protecção civil, estejam aptos a intervir no prazo de 12 horas após o pedido de assistência.

Pelo artigo $5^{\circ}$ da decisão, é determinado à Comissão que deve empreender diversas acções nomeadamente as relativas à criação do CIV e do CECIS, aos programas de formação e ao sistema de lições aprendidas. Refere ainda no capítulo III os procedimentos de resposta a solicitações de ajuda tanto de um estado membro, como de um país extra comunitário e a ligação privilegiada com as agências das Nações Unidas.

A Comissão Europeia põe em prática as decisões do Conselho através de várias acções nomeadamente pela emenda da decisão de 2004/277/EC, de 20 de Dezembro de 2007, em que são definidos vários aspectos associados às equipas e módulos de intervenção nomeadamente:

- A definição de equipas de intervenção e equipas de assistência técnica;

- Os requisitos operacionais e logísticos das diferentes equipas (bombagem, purificação de água, busca e salvamento, suporte médico avançado, combate a fogos florestais com meios aéreos, detecção NBCR .....).

Uma das principais novidades prende-se com a criação de módulos comunitários de protecção civil e ainda a possibilidade de financiamento na área do transporte. 
A título de exemplo referem-se os requisitos a que deve obedecer o módulo de combate a incêndios florestais por meios aéreos (aviões):

- Missão - Contribuir para extinção de incêndios florestais por combate aéreo;

- Capacidades - Dois aviões com 3000 litros cada. Operação contínua;

- Componentes principais - Dois aviões. Três tripulações. Adequado staff técnico. Kit de manutenção de campanha. Equipamento de comunicações. Algum grau de auto-suficiência;

- Disponibilidade - Partida 3 horas após a aceitação da oferta.

\section{Considerações finais}

Como referimos na introdução, no âmbito da Protecção Civil há que encontrar dentro do espaço europeu, nomeadamente na União Europeia, mecanismos que possibilitem actuar em conjunto em dois grandes domínios associados:

- Na prevenção dos acidentes;

- Na minimização dos seus efeitos, nomeadamente numa ajuda mútua oportuna através dos meios mais adequados.

Evidenciamos neste texto um conjunto de iniciativas e acções empreendidas pelas autoridades comunitárias e pelos países membros, fundamentalmente, no sentido minimizar os efeitos de qualquer catástrofe que se venha a abater no espaço europeu, ou a prestação de apoio a terceiros, através de mecanismos que permitam um aviso imediato e uma resposta pronta, estruturada e coordenada.

facto de pouco ou nada se ter referido quanto à prevenção não quer dizer que nada se tenha feito nesse domínio. Efectivamente, muito se tem legislado a nível sectorial no sentido da prevenção de acidentes, nomeadamente, no âmbito do planeamento do espaço, nos sistemas de transportes, na produção industrial, nos sistemas de construção, etc.

Não cabe no âmbito definido para esta intervenção enumerar com detalhe todas estas acções, mas entendo que não posso deixar de fazer referência a um estudo recentemente terminado, produzido no âmbito da Direcção Geral do Ambiente da Comissão Europeia, intitulado "Os Estados Membros e as Políticas de Prevenção - Análise Crítica "em que são investigados os métodos de abordagem à prevenção de acidentes em alguns estados membros - França, Portugal, Suécia e Roménia - e algumas das recomendações nele incorporadas nomeadamente:

- Ser considerada uma maior intervenção da EU neste domínio sem no entanto resultar a criação de novas estruturas;

- Ser considerada uma importante contribuição para a efectiva e boa implementação do sistema de planeamento espacial no sentido da prevenção de acidentes;

- Assumir a relevante importância da investigação nestes domínios nomeadamente nas tecnologias, aptidões, procedimentos e equipamentos;

- Centralizar numa única estrutura os assuntos associados à prevenção tanto a nível da EU como nos países membros;

- Considerar os benefícios que resultam de uma ligação entre as estruturas europeias e outras estruturas ao nível global no domínio da prevenção e redução de acidentes.

Por último, importa realçar a importância que assume no Tratado de Lisboa a cooperação no domínio da protecção civil nomeadamente no Título XXII, o artigo 176. C onde se incentivam os Estados membros a reforçar a eficácia dos sistemas de prevenção de catástrofes e protecção contra as mesmas e de intervenção no socorro em caso de ocorrência dessas catástrofes.

De salientar ainda o teor do artigo 188ㅇ, relativo à cooperação da União com países terceiros afectados por catástrofes e a cláusula de solidariedade incluída no artigo $188^{\circ} \mathrm{R}$ para prestação de apoio em caso de desastres, calamidades e ataques terroristas. 